\title{
The Potential of Sentence Trees in English Grammar Teaching
}

\author{
Danyan Huang ${ }^{1}$ \\ ${ }^{1}$ International College, Guangdong University of Foreign Studies, Guangzhou, China \\ Correspondence: Danyan Huang, International College, Guangdong University of Foreign Studies, Guangzhou, \\ 510420, China.
}

Received: January 8, 2019 Accepted: February 12, 2019 Online Published: February 14, 2019

doi: 10.5539/elt.v12n3p178 URL: https://doi.org/10.5539/elt.v12n3p178

\begin{abstract}
This study aims to explore the potential use of sentence tree-structure in English grammar teaching in college. After combining Schema Theory and Lexical Chunk Theory, the writer proposed the sentence tree-structure tool and tried to apply it in one of her grammar classes in college. During the teaching process, students were asked to analyze long and complex sentences from IELTS reading texts and to write paragraphs and essays for IELTS writing task two topics, with the purpose of applying the new tool in productive activities. Data collection instruments include a pre-test, a post-test, questionnaires and interviews. Both quantitative and qualitative analysis of the data was employed. The difference in students' performance in the pre-test and the post-test revealed that the majority of students showed improvement in their ability to analyze long complex sentences and there was an obvious decline in the number of sentence structure-related grammar errors in their writing. Students' responses in questionnaires and interviews showed a growth in their study motivation and positive perceptions towards the use of this new tool in their grammar learning.
\end{abstract}

Keywords: grammar teaching, lexical chunk theory, schema theory, sentence tree-structure

\section{Introduction}

\subsection{Current Grammar Instruction in College}

As part of English language teaching, grammar teaching has always been a hot research topic, and the importance of grammar has widely acknowledged by linguistics, researchers and teachers alike. In 1987, an academic seminar was held in Lancaster in which highly respected experts like Halliday, Widdowson and leech expressed their recognition of the importance of grammar in language learning. Hu Zhuangling (2006) also agreed to the necessity of grammar teaching while emphasizing the choice of an interesting and easy-to-understand grammar textbook. According to He Lianzheng (2004), a processer in China, if the teacher only adopts the Communicative Approach in grammar teaching, students, although having exposed to a large amount of linguistic input, still cannot acquire many language forms and structures accurately. Some universities have realized this, and realizing the importance of English as an international communicative tool they began to attach importance to grammar teaching for students. However, grammar instruction in college is generally ineffective. After reading a lot of research papers concerning this topic, the writer has summarized several problems in college grammar teaching and learning. The first problem lies in an unclear learning purpose. After being relieved from the heavy study load of high school, most college students feel that English learning, especially grammar learning is of no practical significance apart from the need to pass the exam. The second big problem is in the teaching method. The teaching approach most commonly adopted in grammar classes is the explanation of grammatical rules by the teacher plus a lot of exercises together with mechanical memorization of those rules by students, with a separation of words and grammar learning from the context and a lack of practical use of the rules for real communication purposes such as reading and writing. Therefore, students tend to be de-motivated in such boring classes. The third problem is in the monotonous assessment approach. Multiple choices are usually used as the question type to assess students' understanding and the degree of their mastery of the grammatical rules which have been taught after a teaching session or term.

\subsection{Problems Identified}

In order to further identify the problems which exist in current college grammar classes, the writer conducted a survey in the college where she works as an English teacher. Questionnaire I (see Appendix A) was designed for the survey and questionnaire papers were handed out to all the 325 year-one students, who had just received 
grammar instruction for one semester in a traditional way. Among all the students, 289 have responded to the survey, and thus 289 questionnaires were collected.

The following table shows the statistical analysis of students' responses to all the 15 statements of the questionnaire.

Table 1. Students' views on grammar learning and previous grammar classes

\begin{tabular}{lllll}
\hline Statements & Strongly disagree & Disagree & Agree & Strongly agree \\
\hline 1 & $37.37 \%$ & $50.87 \%$ & $7.96 \%$ & $3.80 \%$ \\
2 & $30.45 \%$ & $48.10 \%$ & $12.80 \%$ & $8.65 \%$ \\
3 & $59.86 \%$ & $36.33 \%$ & $2.77 \%$ & $1.04 \%$ \\
4 & $57.09 \%$ & $17.99 \%$ & $10.73 \%$ \\
5 & $14.19 \%$ & $36.33 \%$ & $26.64 \%$ & $2.08 \%$ \\
6 & $34.95 \%$ & $38.75 \%$ & $23.18 \%$ & $4.51 \%$ \\
7 & $33.56 \%$ & $26.99 \%$ & $30.10 \%$ & $41.87 \%$ \\
8 & $1.04 \%$ & $20.07 \%$ & $30.10 \%$ & $38.07 \%$ \\
9 & $11.76 \%$ & $21.45 \%$ & $33.56 \%$ & $37.38 \%$ \\
10 & $7.61 \%$ & $48.44 \%$ & $14.19 \%$ & $7.96 \%$ \\
11 & $29.41 \%$ & $0 \%$ & $0 \%$ & $100 \%$ \\
12 & $0 \%$ & $51.90 \%$ & $16.26 \%$ & $4.85 \%$ \\
13 & $26.99 \%$ & $42.56 \%$ & $17.99 \%$ & $9.35 \%$ \\
14 & $30.10 \%$ & $15.22 \%$ & $11.76 \%$ & $3.47 \%$ \\
15 & $69.55 \%$ & $11.08 \%$ & $0 \%$ & $0 \%$ \\
\hline
\end{tabular}

As is indicated in the table, the majority of the survey respondents failed to recognize the important role grammar plays in the improvement of their overall English proficiency, and thus had no interest in and motivation for grammar learning. The data also show that most students agreed that the grammar teacher had adopted the traditional way of instruction, that is, giving explanations of grammatical rules and sentence examples and emphasizing exercises and mechanical memorization, without attaching importance to the use of those rules in pragmatic contexts such as reading and writing. Students' response to statement 11 reveals that multiple choice questions were the only question type adopted by the teacher to assess students' performance in the previous grammar teaching session. As for students' view on the teaching approach, the majority believed it was of little or no use in improving their English ability, and it is worth noting that all of the 289 participants agreed that such grammar classes were boring.

Only about one third of the students answered part or all of the open-ended questions in part three of the questionnaire. Among them, most cited passing the final examination as the main purpose of attending grammar classes. According to the responses, the biggest obstacle for them was having little or no belief in mastering grammatical rules, and although some of them had spent a lot of time doing exercises, they failed to apply the rules in their productive activities. As the answer to the last question, most of the respondents suggested the future grammar teacher should adopt more interesting and stimulating method to strengthen their study motivation and to help them deal with IELTS reading materials and writing topics since they have to get a band 6 or 6.5 in order to get the chance to study abroad.

The data gathered from the questionnaire show an overall compliance with the problems identified by the research conducted by previous researchers on English grammar teaching in college, which urges the current writer to carry out her own research to seek for a possible solution. 


\section{Literature Review}

\subsection{Schema Theory and English Teaching}

\subsubsection{Definition and Classification of Schema}

Schema, originally a term in psychology, was first proposed by Kant, a German psychologist, in 1781. According to him, schema is a transcendental cognitive structure, the result of the interaction between people's senses and the objective world, and thus schema is the link between concepts and the object perceived (Gu, 2007). In the early $20^{\text {th }}$ Century, a Swiss psychologist Piaget introduced the concept of schema into cognitive psychology. He defined schema as an organized repetitive pattern of behavior and the starting point and a core unit in cognitive structure. According to him, schemas have no clear beginning, and they are developed from earlier schemas which can trace back to the most primitive reflections and instinctive movements (Zhang, 2007). In other words, schemas are always changing. A person's first schema comes from his/her parents through genetic inheritance, and after constant interaction with the world, the schema develops and evolves, which is the process of schema construction. In 1932, Artificial Intelligence Scientist F. C. Bartlett defined schema as a dynamic construction of people's prior experience in the brain, and applied the concept to the research on memory and knowledge construction (Gu, 2007). Later, Artificial Intelligence Scientists D. E. Rumelhart (1980) and P. L. Carrel (1983) further developed this theory and applied it into foreign language teaching by exploring the psychological process of foreign language learning and understanding reading materials. Influenced by the research in the field of Artificial Intelligence, J. Anderson developed schema theory further as part of cognitive psychology in 1985 and promoted the idea that schema is one of the ways that information stores in long-term memory and it is a huge information structure centered around a common topic or subject, which consists of information levels and sub-levels (Zhang, 2007).

Psychologists proposed two schema categories: content schema and form schema. The former relates to the events of a given situation and refers to the framework of the object perceived or the reality of the object and the latter refers to the background knowledge of the discourse rhetoric structure. According to Rumelhart (1980), any schema stored in the brain can be viewed as either content schema or form schema; the former includes cultural, pragmatic and professional knowledge, which forms the framework of perceptions and events while the latter includes knowledge of literary symbols, phonetics, words, sentences and semantic structures.

\subsubsection{Application of Schema Theory}

Schema theory has been used to describe the process of perceiving new information in cognitive psychology, and as a result it is also applied into foreign language learning, especially the development of reading skills. Recent studies show that schema theory is mainly used in the comprehension of text information in the process of language acquisition. Zhongyi, Lu and Zhe, Wang did an empirical study and proved that schema-based analysis of English argumentations could improve reading skills of learners (Kang, 2011). Guoju, Lu investigated the influence of form schema on listening comprehension through empirical comparison (2007). Lidi, Wang adopted schema theory in his study on interpretation and revealed that content schema played a critical role in translation and especially interpretation process (Yang \& Deng, 2007). Tengfei, Yu (2013) conducted a study into the areas into which the schema theory had been employed in L2 language acquisition in China during 20 years and found that this theory had been widely used in reading, listening, discourse analysis, textbook compilation, translation and vocabulary acquisition, among which the teaching of reading was the area where it is most commonly used. In the past few years, schema theory has also been adopted in grammar teaching in both secondary and tertiary education in China. After employing this theory in her language teaching classes and helping senior high school students to understand and then master grammar rules in a more organized and interesting way, Liyong, Song finished her graduation thesis as an English major in college in 2010. Foreign language teachers such as Fang, Wang (2015) and Li, Wang (2016) have conducted research into the application of this theory to English grammar teaching in college and presented some innovative ways to help students construct schemas while learning grammatical rules, thus promoting students' motivation for grammar learning.

\subsection{Lexical Chunk Theory and English Teaching}

\subsubsection{Definition and Classification of Lexical Chunks}

The consensus of academic opinion is that the concept of lexical chunks was first proposed by Becker (1975), who regarded lexical chunks as phrasal lexicons, a fixed or semi-fixed pattern between traditional grammar and vocabulary. According to Pawley and Syder (1983), they were lexicalized sentence stems which were similar to sentences in length and whose grammar pattern and semantic meaning were fixed and accepted as part of the culture in which the language was spoken. Nattinger and DeCarrico (1992) used "lexical phrase" to refer to this 
language unit, something between traditional words and sentences, the combination of form and function which appears more frequently in communications than sentences assembled based on grammatical rules. The term "lexical chunk" was proposed by Lewis (1993), who conceived lexical chunks as frequently used combinations of multi words with fixed structures and stabilized meanings. Moon (2002) regarded this special language unit as multi-word unit composed of two or more inseparable words with semantic and syntactic meaning. Although experts' opinions vary as to how to define the lexical or sentence unit, the consensus was that it is a lexical sequence consisting of two or more words with lexical, grammatical and pragmatic functions. The current writer adopted Lewis' definition and regarded this language unit as a lexical chunk or sense group while understanding the structure of a complex sentence.

As to the classification of lexical chunks, scholars hold different views too. Becker (1975) classified lexical chunks into six categories from structure and function perspective: poly words, phrasal constraints, meta-messages, sentence builders, situational utterances and verbatim texts. Similarly, Nattinger and DeCarrico (1992) put forward a four-category classification according to the length, grammar, form and stability of lexical chunks, which were poly words, institutionalized expressions, phrasal constraints and sentence builders. Lewis grouped lexical chunks into four types according to the syntactic function and semantic relation between words: words \& poly words, high frequency collocations, fixed or institutionalized expressions and sentence frames and heads (1997). The current writer mainly adopted Lewis' classification and believed that an English sentence is composed of several phrases or sense groups of many types such as noun phrase, verb phrase, adjective phrase, adverbial phrase and prepositional phrase.

\subsubsection{Application of Lexical Chunk Theory}

The application of Lexical Chunk Theory in the field of language teaching has been extensively researched both abroad and at home. Nattinger and DeCarrio (1992) explained how lexical chunks were defined, classified and used in writing classes. Lewis (1993) proposed lexical chunk teaching approach. This theory was also widely adopted in the teaching of reading, writing, listening, speaking and grammar. Li, Jie and Schmitt, Norbert (2009) employed longitudinal method to conduct a study into how a Chinese student used lexical chunks in English writing and found that the use of lexical chunks helped to develop academic reading skills. S. Sadighi and R. Sahragard (2013) investigated into the influence of different mastery degree of lexical chunks on the reading capability of Iranian language learners and proved that there was a positive correlation between the mastery of lexical chunks and reading abilities. MA Hong and Li Chunling (2016) did a study on the relation between Lexical Chunk Theory and English reading fluency of college students and showed that it positively impacted their vocabulary accumulation, reading speed, accuracy and fluency. Nosrat Ranjbar, Abdolreza Pazhakh and Bahman Gorijian's research revealed that lexical chunks could contribute to the fluency of paragraph writing by researching Iranian second language learners' writing abilities. Malek Mhedhbi (2014) studied the effectiveness of lexical chunk awareness in promoting business English writing levels and found that the experimental group and control group had a dramatic difference in their performance. Juan Wang and Yue Yang (2014) did an empirical study into the use of lexical chunk teaching approach for a semester and discovered that students' listening competence has been greatly improved. Xiaoyu He (2016) researched the listening abilities of non-English majors and pointed out that the combination of Lexical Chunk theory and Schema Theory was of great help in developing students' listening skills and could help shift students from passive learners to positive learners. Ping Yuan and Fengrong Guo (2010) conducted an empirical study on the relation between lexical chunks and speaking fluency of English majors and proved that the mastery of lexical chunks contributed to the improvement of speaking abilities. Wuyun Xiao (2011) adopted the teaching mode of "write and say" based on Lexical Chunk Theory and showed that this teaching approach could better students' speaking skills. Zhengping $\mathrm{Li}$ (2018) used this theory to guide grammar teaching and demonstrated that lexical chunks could help to teach grammar to high school students in a more effective and interesting way than the traditional approach. Ying Huang (2018) adopted grammar chunk teaching approach in her own language classes and succeeded in helping students acquire grammar rules and thus improve their writing competence.

\subsection{Sentence Tree-structure and English Teaching}

Based on Schema theory and Lexical Chunk Theory, the writer has come up with the idea of English sentence tree-structure to help her students to master English grammar and understand and compose English sentences accurately. Each sentence is regarded as a tree with leaves and branches. The basic sentence unit, that is the subject plus the predicate, is the tree trunk. The various types of modifiers such as attributives, adverbials and appositives are tree branches. Every simple or complex sentence has only one trunk while each compound sentence has two trunks connected by a coordinating conjunction like "and", "or" and "but" and these two trunks are equally important just as two persons who get married and start a bigger family. Each sentence tree can be 
thick and broomy with a lot of leaves and branches. Single-word modifiers such as adjectives and adverbs are conceived as tree leaves and phrases or sense groups are called branches. Phrases or sense groups are categorized as different types: noun phrases, verb phrases, prepositional phrases, adjective phrases, adverbial phrases, participle phrases (including present participles and past participles), infinitive phrases and appositive phrases. Noun phrases and verb phrases form the trunk, and other types of phrases are branches. The branches are connected to the trunk at the nodes which are prepositions, adjectives, participles, the infinitive and such punctuation marks as the comma ",", the colon ".", the dash "-_" and the brackets "()". Branches and leaves can be added to both the trunk and other branches to make the tree thicker. In order to identify the trunk of the sentence tree, the nodes and branches should be identified first. Then the tree can be drawn to clearly show the structure of the sentence and how the trunk and branches are connected. For example, in this long sentence "Only Germany, with incentives to business to encourage the employment of older people, and France, with the introduction of legislation making it illegal to use age barriers in recruitment —or to make employees redundant because of their age, have done anything substantive to combat age discrimination.", the basic sentence unit "Germany and France have done anything substantive." is the trunk, and "with incentives to business", "to encourage the employment of older people", "with the introduction of legislation", "making it illegal to use age barriers in recruitment", "- or to make employees redundant because of their age" and "to combat age discrimination" are branches with the nodes of "with", "to", "with", "making", "-_" and "to" respectively. It is worth noting that some branches can be sub-divided into several smaller branches, as the branch "making it illegal to use age barriers in recruitment" can be divided into "making it illegal", "to use age barriers" and "in recruitment".

The writer believes the idea of sentence trees can help students to deal with long difficult sentences and even help them write such sentences themselves without making effort to understand abstract terms in grammar. It may be a good way to replace the explanation of many grammatical rules so that grammar classes may become less boring and frustrating.

\section{Method}

\subsection{Research Questions}

The questions addressed in the research were:

1) Whether will the sentence tree-structure approach strengthen students' motivation to learn English grammar?

2) How do students perceive the use of the sentence tree-structure approach in English grammar learning?

3) Whether will the sentence tree-structure approach help students to deal with long complex sentences in reading texts and write correct sentences in writing tasks?

\subsection{Participants}

The teacher conducted this research in her own English as second language class, which consisted of 32 mixed-sex students with their ages ranging from 17 to 19 . The students were on a $2+2$ higher education program which is a joint program between the college where the writer works and a British university. In the first two years the students study in the Chinese college to improve their English proficiency trying to gain a band 6.5 in IELTS and in the next two years they will study abroad after they meet the IELTS band requirement and all the course requirements. They attend an English grammar class for 80 minutes a week and have studied in the college for half a year.

\subsection{Instruments}

Quantitative data were mainly collected through the pre-test and post-test and the comparison between the test results to show whether students' abilities in understanding long complicated sentences in reading materials and writing correct sentences have been improved through the introduction of the sentence tree-structure in grammar teaching. Both qualitative and quantitative data were also collected via two questionnaires (written in L1), with one to identify the problems students have in previous English grammar classes (Questionnaire I) and the other to gain students' feedback on the effectiveness of the new grammar teaching approach adopted in this semester as well as their motivation change in grammar learning (Questionnaire II), and several interviews (also conducted in L1) to elicit students' perception of this newly-adopted approach and their suggestions for future classes.

\subsection{Research Process}

The research project lasted for 19 weeks. Before the semester started, questionnaire I (see Appendix A) was 
designed and handed out to all the first-year students (altogether 325) and 289 responses were collected to identify the problems existing in prior grammar classes. At the beginning of the semester, the teacher asked her student subjects to take a pre-test which consisted of 20 long complex sentences extracted from the reading passages of Cambridge IELTS series and a task two topic of IELTS writing test. In the first part the students were required to underline the subject, predicate and the object (if there is one) of each sentence in order to test their understanding of its main structure and the time they had spent in doing that was recorded by the teacher. In the second part, they were supposed to compose an essay based on the given writing topic, and after they finished, the teacher calculated the number of grammatical errors in their compositions and classified these errors into categories. Then the teacher introduced the sentence tree-structure teaching method to her student participants and explained that the purpose of the grammar class is to prepare them for IELTS, especially for the reading and writing test so that the students would have a clear purpose in mind and know that their effort would lead them to the result they desired.

The instruction process could be divided into three main steps. In the first step, the teacher introduced the five most basic sentence structures, categorized the verbs commonly used for each sentence structure and then asked students to make up sentences by using these verbs. In the second step, the teacher explained what the sentence tree is composed of, how to identify the node for each phrase or sense group and then categorize different types of sense groups beginning with particular nodes. Then, she showed students long and complex sentences helping them to find out sense groups and drawing sentence trees. During this step the students would realize that the trunk of each sentence tree was one of the five basic sentence types and all the branches were sense groups in the sentence. In the third step, the subjects were asked to add leaves (singular word modifiers) and branches (sense groups) to the basic sentence trees that they had created during the first step to make long sentences. During this step, students would pay attention to the completeness of each sentence tree, the relation between the trunk and each sense group and the necessity of the appropriate use of nodes (punctuation marks, participles, prepositions, subordinators and coordinating conjunctions). During the whole teaching process, IELTS reading texts and writing topics were employed to create a meaningful pragmatic context for grammar learning.

At the end of the semester, the student participants were asked to take a post-test which was similar to the pre-test in terms of the question number, types and complexity. The data here were collected in the same way with the pre-test so that the amount of time the students spent in figuring out the sentence trunk for all the long complex sentences in the first part of the test and the number of correct answers for this part as well as the number of grammatical errors in their writing for the second part of the test could be compared. Questionnaire II (see Appendix B) was distributed to all the student subjects and interviews were conducted with two male and two female students so that their feedback on motivation change and attitudes towards this new teaching method could be generated.

\section{Results}

\subsection{Dealing With the First Two Research Questions}

\subsubsection{Quantitative Analysis}

To address the first and second research question, both quantitative and qualitative analysis was done based on students' responses to Questionnaire II. The questionnaire papers were handed out to all the 32 students and all of them were completed and collected. Part one of the questionnaire was about students' personal information. Part two included 12 items with the first half concerning students' motivation change while the rest being about their attitudes towards the new teaching method. Part three were three open-ended questions aiming to induce students' explanations for their preference, the problems they encountered and their suggestions for future improvement.

Table 2. Students' views of the effect of English sentence tree-structure on their study motivation ( $N=32)$

\begin{tabular}{lllllll}
\hline Items & $1(\mathrm{n})$ & $2(\mathrm{n})$ & $3(\mathrm{n})$ & $4(\mathrm{n})$ & $5(\mathrm{n})$ & $6(\mathrm{n})$ \\
\hline Strongly disagree & 0 & 0 & 0 & 0 & 0 & 0 \\
Disagree & 1 & 0 & 0 & 2 & 3 & 4 \\
Neutral & 5 & 3 & 7 & 4 & 6 & 7 \\
Agree & 21 & 23 & 22 & 21 & 20 & 17 \\
Strongly agree & 5 & 6 & 3 & 5 & 3 & 4 \\
\hline
\end{tabular}




\begin{tabular}{lllllll}
\hline $\begin{array}{l}\text { Agree and strongly } \\
\text { Agree (\%) }\end{array}$ & 81.25 & 90.63 & 78.13 & 81.25 & 71.88 & 65.63 \\
\hline
\end{tabular}

Table 2 shows students' responses to items 1-6 of the questionnaire. The majority of students acknowledged that their motivation for grammar study has been lifted after the teacher adopted the English sentence tree-structure approach, as indicated by the percentage of them who agreed or even strongly agreed with the statements. More specifically, over $90 \%$ of the respondents agreed that they became more attentive in grammar classes than before. About $80 \%$ of them admitted their strengthened willingness, confidence and expectations for progress in grammar learning. But only near $72 \%$ of students have actively participated in class activities and even less (about 66\%) could finish homework as required, which reveals that other problems may have frustrated students' effort and need to be identified.

Table 3. Students' perception of the new grammar teaching approach $(\mathrm{N}=32)$

\begin{tabular}{lllllll}
\hline Items & $7(\mathrm{n})$ & $8(\mathrm{n})$ & $9(\mathrm{n})$ & $10(\mathrm{n})$ & $11(\mathrm{n})$ & $12(\mathrm{n})$ \\
\hline Strongly disagree & 0 & 0 & 0 & 0 & 0 & 0 \\
Disagree & 0 & 0 & 0 & 4 & 0 & 3 \\
Neutral & 4 & 3 & 0 & 7 & 0 & 4 \\
Agree & 23 & 21 & 30 & 18 & 30 & 21 \\
Strongly agree & 5 & 8 & 2 & 3 & 2 & 4 \\
Agree and strongly & 87.5 & 90.63 & 100 & 65.63 & 100 & 78.13 \\
Agree (\%) & & & & & & \\
\hline
\end{tabular}

Table 3 presents students' perception of the effect of the English sentence tree-structure teaching approach. Responses to item 9 and 11 showed that all of the students were made more aware of the importance of figuring out the structure before fully understanding a complex sentence and of the necessity of writing complete and accurate sentences. The response to item 7 and 8 shows that near $90 \%$ of the respondents thought the new approach was easier to understand and over $90 \%$ agreed that it is more interesting than the traditional one. Near $80 \%$ of the students agreed having made less grammatical errors under the guidance of this new approach but only about $66 \%$ of them thought it has helped them to quickly and accurately identify sentence structures while reading IELTS materials, indicating that other factors have prevented them from achieving the intended goal and need to be identified as well.

\subsubsection{Qualitative Analysis}

The third part of Questionnaire II were three open-ended questions meant to elicit students' attitudes towards the application of the new grammar teaching method, the problems they encountered during study as well as their suggestions for future perfection of this method.

The answers to the first question indicated that 28out of 32 students preferred the new grammar teaching approach to the old one mainly for the reason that it gave them a more clear purpose for learning the course and was easier to understand since the tree structure left a more vivid and long-lasting impression on their mind. The answers to the second question revealed that the biggest challenge identified by the students was a small vocabulary, which explained why some of them failed to quickly and effectively figure out the structure of compound sentences in reading and accurately express their ideas in essay writing even with the help of the new approach. When asked to give suggestions for the future (the third question), most of those who had responded to the question recommended a systematic study of important words and expressions before the introduction of this grammar teaching approach so that they could be better prepared.

Apart from the responses to the open-ended questions in Questionnaire II, qualitative data was also gained from interviews conducted with two male students and two female students. Three questions were asked: 1) How do you think of the English sentence tree-structure method adopted in grammar classes this semester? 2) What improvement have you noticed through the completion of reading and writing exercises? 3) What suggestions do you have for the future improvement of the approach and English grammar course as well? 
All of the interviewees perceived the new grammar instruction method positively, as shown in the following extracts of their statements responding to the first interview question:

[S1] I like the way the teacher taught us how to understand and write English sentences. Every sentence was compared to a tree, and I think it is less boring and more effective than the traditional method.

[S2] I used to be unwilling to attend grammar classes because I could never understand those abstract rules and technical terms and I'm afraid I never succeeded in doing the exercises correctly. Fortunately with the introduction of the English tree-structure, I started to know the structure of a sentence and how to write complete sentences.

[S3] This teaching method is wonderful. I felt motivated in every grammar class this semester because I knew that the teacher would help us to solve real problems which we would encounter when we take IELTS in the future.

[S4] The new teaching method is much better than the old one. To be honest, the previous teacher's grammar explanations gave me headaches and I was really fed up with multiple choice exercises. I thought grammar learning was useless and ineffective. But with the new method, I could sense a clear purpose of study and my confidence built up even though I still couldn't finish the reading and writing tasks as required due to my poor vocabulary.

All the four participants also noticed some improvement in their reading and writing skills, as indicated in the following extracts which are part of their answers to the second interview question.

[S1] Before this semester, I had read the sentences in a passage word by word, and hadn't fully got the meaning of long complex sentences even though I had known each singe word. After this semester, I realized that a sentence could be treated as the combination of several chunks or sense groups and some were more important than others in conveying the meaning.

[S2] Both my reading and writing abilities have been improved. Now whenever I read or write a sentence I will pay attention to the structure, and I will use what I have learnt from the grammar course in my future study.

[S3] After the study of this semester, I feel less terrified by IELTS. Although there are still many new words in the reading materials I can read the passages more quickly and get more meanings from the sentences. I can also write many correct sentences in English, which sounded almost impossible in the past because I had always been criticized by my grammar teachers in high school.

[S4] I was reluctant to write English essays before, because I was always frustrated by too many grammar mistakes that I tended to commit. Now I feel much more confident, and I know how to avoid some structure-related errors. I think that is the biggest improvement that I have achieved in this semester.

Problems also arise, as revealed in the following:

[S1] My reading speed was still very slow. There were too many new words to me in the IELTS reading passages. And with too few English words in my mind I still couldn't express my opinions clearly in essay writing.

[S4] The IELTS reading materials were too difficult for me and it seemed that 70\% of the words were new to me.

As the response to the third interview question, all the four students suggested that the teacher should help them to build up vocabulary systematically while implementing this teaching approach, which is in agreement with the answers to the last open-ended question in Questionnaire II.

\subsection{Dealing with the Third Research Question}

To address the third research question, quantitative data were collected and analyzed based on the subjects' performance in pre-test and post-test, as shown in table 4 and 5 below.

Table 4. Comparison of students' performance in reading tests

\begin{tabular}{lllll}
\hline & Average time used & Highest point $(\mathrm{N}=20)$ & Lowest point $(\mathrm{N}=20)$ & Mean of accuracy $(\mathrm{N}=20)$ \\
\hline Pre-test & $46^{\prime} 34^{\prime \prime}$ & 14 & 4 & 8.56 \\
Post-test & $37^{\prime} 21^{\prime \prime}$ & 20 & 6 & 12.25 \\
Difference & $9^{\prime} 13^{\prime \prime}$ & 6 & 2 & 3.69 \\
\hline
\end{tabular}


Table 4 reveals a dramatic contrast in students' performance between the reading part of the pre-test and that of the post-test. In the pre-test, it took all the 32 students the average time of 46 minutes and 34seconds to finish analyzing all the 20 long complex sentences, while in the post-test, the average time used was only 37 minutes and 21 seconds, near 10 minutes less, which indicated a clear improvement in reading speed. As to the accuracy of students' performance, the mean value in the post-test was 12.25, in sharp contrast with that in the pre-test (at 8.56). And in the pre-test, the lowest point was 4 , (meaning that the student who did the worst got only 4 correct answers), and the highest point was 14, (meaning that the student who did the best got 14 answers correct), whereas in the post-test the number was 6 and 20 respectively, which showed a big progress too.

The subjects' performance in writing tests has also been analyzed. The teacher classified the grammatical errors that the students had made into six categories according to their frequency. Category 1 refers to confusing shifts which include confusing shifts in person, tense and number as well as subject-verb disagreement. Category 2 is sentence fragments including dependent-word fragments (clauses begging with a sentence connector but without the trunk of a sentence), missing-subject fragments and "-ing" and "to" fragments. Category 3 is run-on sentences (two or more independent sentences incorrectly joined by a comma without a coordinating conjunction or sentence connecter). Category 4 refers to misplaced modifiers which include misplaced prepositional phrases, attributive clauses and adverbial modifiers. Category 5 means two-or-more-predicate sentences (sentences with two or more verbs or verb phrases but without a coordinating conjunction or sentence connecter). Category 6 refers to dangling modifiers, which are phrases or clauses at the beginning of a sentence that either have nothing to modify or that modify the wrong element in the clauses to which they are attached.

Table 5. Comparison of students' grammatical errors in writing tests $(\mathrm{N}=32)$

\begin{tabular}{llllllllllllll}
\hline & \multicolumn{1}{l}{ category 1} & \multicolumn{2}{c}{ category 2} & \multicolumn{2}{c}{ category 3} & \multicolumn{2}{c}{ category 4} & \multicolumn{2}{c}{ category 5} & \multicolumn{2}{c}{ category 6 } \\
\hline \multirow{3}{*}{ Pre-test } & total & mean & total & mean & total & mean & total & mean & total & mean & total & mean \\
Post-test & 98 & 3.06 & 71 & 2.22 & 67 & 2.09 & 52 & 1.63 & 50 & 1.56 & 26 & 0.81 \\
Difference & 96 & 3.00 & 14 & 0.44 & 9 & 0.28 & 12 & 0.38 & 7 & 0.22 & 27 & 0.84 \\
& 2 & 0.06 & 57 & 1.78 & 58 & 1.81 & 40 & 1.25 & 43 & 1.34 & -1 & -0.03 \\
\hline
\end{tabular}

It can be seen clearly in the table that the biggest change in the students' performance in the two writing tests was in the number of errors all the 32 students made in category 3 (run-on sentences) and category 2 (sentence fragments), with the difference of 58 and 57 respectively, which means that with the help of sentence tree-structure tool the number of these two types of errors has greatly decreased. Following this was the difference in the number of errors in category 5 (two-or-more predicate sentences) and category 4 (misplaced modifiers), at 43 and 40 respectively. The error number in the remaining two categories (confusing shifts and dangling modifiers) remained more or less unchanged. All this reveals that the new teaching tool was effective in helping students understand English sentence structures and thus help them make less structure-related mistakes in writing, but it was of no use in tackling other types of errors.

\subsection{Conclusion}

From the above qualitative and quantitative analysis, it is evident that most of the subject students have had a positive attitude towards the new grammar teaching method and have experienced an upward change in both their study motivation and their reading abilities (shown by their improved reading speed and accuracy) and writing capabilities (indicated by less sentence structure-related errors they committed). Despite this desirable result, the fact that some students with a small vocabulary have not benefited from this teaching approach shows that more preparation work needs to be done before or while this approach is employed. In addition, that some students did not quite approve this new approach indicates that it is not without flaw and that more research needs to be carried out to perfect it in the future.

\section{Discussion}

The present empirical study was conducted to investigate the potential effectiveness of the English sentence tree-structure approach to grammar teaching, created by the writer after combing Schema Theory and Lexical Chunk Theory, in assisting students in understanding long complicated sentences while reading IELTS exam papers as well as composing grammatically sound sentences while writing IELTS topics. The study demonstrates that the students showed a positive perception of this approach overall and they admitted having changed their 
motivation level favorably. It also reveals that their active participation in reading and writing tasks in class has contributed to their better understanding of sentence structures and better prepared them for IELTS they are expected to take within the coming two years.

However, this research has several limitations. The first limitation is in the writer's insufficient knowledge about the theories that have been adopted in the current study and lack of experience in applying the tree-structure tool, and as a result a more systematic and flawless tool could not have been created. The second limitation lies in the research design. This experimental research uses the pre-test post-test design, but there is not a control group, which reduces the researcher's confidence in the conclusion. Another problem is with the need for researcher triangulation. According to Denzin (1978), the guarantee of research quality requires four types of triangulation, which are data triangulation, theory triangulation, methods triangulation as well as researcher triangulation. In this study, the first three types of triangulation have been achieved, but the fourth one is somewhat neglected. So, the involvement of more researchers needs to be considered in future studies in this field.

\section{Acknowledgments}

Firstly I would like to extend my sincere gratitude to Professor Chen Linhan, my postgraduate supervisor and my close friend, for the inspiration and guidance that he has given me during the research, and to Professor Xu Zhanghong for his recommendation of the journal to publish the research.

My heartfelt thankfulness also goes to my colleagues, especially those with whom I share the same office, for their selfless support and helpful advice.

Lastly, I would like to express my thanks and indebtedness to my husband, who has offered me the technical assistance whenever I needed it, and my mother-in-law, who has helped to take care of my four-year-old son and do the housework while I was fully engrossed in my research work.

\section{References}

Bartlett, F. C. (1932). Remembering: An experimental and social study. Cambridge: Cambridge University Press.

Becker, J. (1975). The phrasal lexicon. Cambridge, Mass: Bolt, Beranek and Newman. https://doi.org/10.3115/980190.980212

Carrell, P. L., \& Eisterhold, T. C. (1983). Schema theory and EFL reading pedagogy. Cambridge: Cambridge University Press.

Denzin, N. K. (1978). The research act: A theoretical introduction to sociological methods (2nd ed.). New York: McGraw-Hill.

Gu, B. (2007). The application of schema theory in the teaching of English writing in College. Foreign Languages and Literature Research, 18, 23-24.

He, L. Z. (2004). Form teaching in communicative language classrooms. Foreign Languages and Foreign Language Teaching, 7, 45-46.

He, X. Y. (2016). Non-English majors' listening teaching based on lexical chunk theory and schema theory. English Language Teaching, 9(2), 142-147. https://doi.org/10.5539/elt.v9n2p142

Hong, M., \& Li, C. L. (2016). A case study of lexical chunk theory and its impact on reading fluency. Cross-Cultural Communication, 12(3), 35-39.

Hu, Z. L. (2006). Several thoughts on English teaching in China. Lunwenwang.com/Freepaper/English/English Teaching/200612/Freepaper-305.

Huang, Y. (2018). Grammar chunk approach in English writing classes. English Square, 6, 119-121.

Kang, L. X. (2011). Literature review on schema theory in China. Social Science in Henan, 19, 180-181.

Lewis, M. (1993). The lexical approach (pp. 34-77). London: language Teaching Publications.

Lewis, M. (1997). Implementing the lexical approach: Putting theory into practice. Hove, England: Language Teaching Publications.

Li, J., \& Norbert, S. (2009). The acquisition of lexical phrases in academic Writing: A longitudinal case study. Journal of Second Language Writing, 18(2), 85-102. https://doi.org/10.1016/j.jslw.2009.02.001

Li, Z. P. (2018). A study on the application of lexical chunk theory in high school English grammar teaching. English Square, 6, 163-164.

Lu, G. J. (2007). The impact of discourse structure schema and intonation pattern on English listening 
comprehension. Foreign Language Teaching and Research, 2, 117-122.

Mhedhbi, M. (2014). Lexical bundles and the construction of an academic voice in business writing. Advances in Language and Literary Studies, 5(6), 1-9.

Moon, R. (2002). Vocabulary connections: Multi-word item in English. In N. Schmitt, \& M. MeCathy (Eds.), Vocabulary description acquisition and pedagogy. Shanghai: Shanghai Foreign Language Education Press.

Nattinger, J., \& DeCarrico, J. (1992). Lexical phrases and language teaching. Oxford: Oxford University Press.

Ranjbar, N., Pazhakh, A., \& Gorjian, B. (2014). The effect of lexical bundles on Iranian EFL learners linguistic production fluency. International Education Studies, 5(4), 243-251.

Pawley, A., \& Syder, F. (1983). Two puzzles for linguistic theory: Native-like selection and native-like fluency. In J. Richard, \& R. Schmidt (Eds.), Language And Communication. London: Longman.

Rumelhart, D. E. (1980). Schemata: The building blocks of cognition. In R. J. Spiro et al. (Eds.), Theoretical Issures in Reading Comprehension. Erl Baum, Hillsdale.

Sadighi, S., \& Sahragard, R. (2013). The effect of lexical collocational density on the Iranian EFL learners' reading comprehension. The Journal of Teaching Language Skills, 1(1), 1-11.

Wang, F. (2015). A brief discussion about the application of schema theory in the teaching of college English grammar. Journal of Hetao College, 4, 64-66.

Wang, J., \& Yang, Y. (2014). Multimodal teaching intervention into lexical chunk learning and the improvement of listening comprehension abilities. Teaching Research, 6, 43-52.

Wang, L. (2016). A study on the application of schema theory in college grammar teaching. English Square, 6, 115-116.

Xiao, W. Y. (2011). An empirical study into the teaching mode of "write and say" based on lexical chunks. Foreign Language Teaching, 5, 52-55.

Yang, P., \& Deng, L. H. (2007). An empirical study on the application limitations of schema theory in listening teaching. Foreign Languages in China, 3, 49-53.

Yu, T. F. (2013). Literature review on schema theory and foreign language teaching research in China-Based on the statistical analysis of 31 core journals in foreign languages during 20 years (1993-2012). Overseas English, 4, 263.

Yuan, P., \& Guo, F. R. (2010). A correlation study on lexical chunks and speaking fluency of second language learners. Foreign Language World, 1, 54-62.

Zhang, X. (2007). The application of schema theory in the teaching of English writing in college. Science and Technology Information, 9, 12-13.

\section{Appendix A}

\section{Questionnaire I: Students' Attitudes Towards Grammar Learning and Perceptions of Grammar Classes}

Part one: Demographic Information

(1) Gender

(2) Age

Part two:

The following are statements intended to find out your attitudes towards English grammar and perceptions of grammar classes. For each of the statements, please choose your answer by ticking the appropriate box in the table below:

\begin{tabular}{llll}
\hline Statements & $\begin{array}{l}\text { Strongly } \\
\text { disagree }\end{array}$ & disagree & $\begin{array}{c}\text { agree } \\
\text { strongly } \\
\text { disagree }\end{array}$ \\
\hline 1. & My mastery of English grammar is good. & & \\
2. $\quad$ Grammar is important in English learning. & & \\
3. I am interested in English grammar. & & \\
\hline
\end{tabular}


4. I have spent a lot of time in learning English grammar.

5. English grammar can help me to understand long and complex sentences in reading texts.

6. English grammar can help me to write accurate sentences.

7. The most frequently used teaching approach by my grammar teacher is giving explanation and sentence examples.

8. My grammar teacher always asks me to do a lot of exercises after each lesson.

9. My grammar teacher always encourages me to memorize grammatical rules.

10. My grammar teacher helps us to use grammatical rules to read English texts and write correct sentences for writing topics.

11. The grammar teacher only uses multiple choice question type in the final examination.

12. Clear explanation of grammatical rules is important for my English study.

13. Doing grammar exercises is useful for me to improve my English proficiency.

14. Overall, the English grammar class is useful.

15. Overall, the English grammar class is interesting.

Part three: open-ended questions

1. For what purpose do you learn English grammar?

2. What is the biggest obstacle for you to learn grammar well?

3. What is your suggestion for future grammar classes?

\section{Appendix B}

\section{Questionnaire II}

Part one: Demographic Information

(1) Gender

(2) Age

Part two: the influence of English sentence tree-structure approach on study motivation and students' attitude change

The following are statements intended to find out the perceived effect of the new teaching approach in English grammar class. For each of the statements, please choose your answer by ticking the appropriate box in the table below:

\begin{tabular}{lccc}
\hline statements & $\begin{array}{l}\text { Strongly } \\
\text { disagree }\end{array}$ & Disagree Neutral Agree & $\begin{array}{l}\text { Strongly } \\
\text { agree }\end{array}$ \\
\hline
\end{tabular}

1. I was more willing to learn English grammar.

2. I was more attentive in the English grammar class.

3. I had more expectations for my own performance and progress during this course.

4. I had more confidence in learning grammar well. 
5. I always participated actively in classroom activities.

6. I could finish my homework as expected.

7. Compared with the teaching method adopted last semester, English sentence tree-structure approach is easier to understand.

8. Compared with the old teaching method, this new approach is more interesting.

9. I was more aware of the importance of the sentence structure in understanding the meaning of sentences.

10. I could quickly identify the structure of complex sentences after one-semester's study.

11. I was more aware of the need to write complete and correct sentences.

12. I made less grammatical errors while writing the essay.

Part three: open-ended questions.

1. Do you prefer the old grammar teaching method which focuses on explanation and exercises or the sentence tree-structure approach which emphasizes learning by using? Why?

2. What problems did you meet with when you were doing reading or writing tasks?

3. What suggestions do you for the teacher to improve this teaching method in the future?

\section{Copyrights}

Copyright for this article is retained by the author(s), with first publication rights granted to the journal.

This is an open-access article distributed under the terms and conditions of the Creative Commons Attribution license (http://creativecommons.org/licenses/by/4.0/). 